\title{
Incubation publication model for quality improvement of scientific book: A case study of books on functional food
}

\section{Rahmi Lestari Helmi and Mochammad Wahyu Ghani}

\author{
Lembaga Ilmu Pengetahuan Indonesia
}

Paper Type:

Case Study

Submitted 2 May 2019 Accepted 22 December 2019

\section{Abstract}

Background of the study: Lack of information on functional food ingredients in book form has encouraged LIPI Press to create an incubation scheme for scientific publications that can Accelerate the process of publishing scientific texts, roommates are always constrained by the halt of creative ideas from the authors.

Purpose: The concept of implementing a scientific publication incubation scheme involves the process of transfer of knowledge and learning is a complex process and involves many parties, from the stage of ideas (ideation) until the book becomes available and is worth reading by the target reader.

Method: The novelty aspect of research in the context of this activity is the implementation of the book publishing scheme (scientific), thus the need to establish an appropriate model.

Findings: The concept of this the model emphasizes the aspects of knowledge management and communication between actors in publications items, namely, writers, experts, and publishers (editors).

Conclusion: In this case, knowledge management will identify the most influential factors in supporting the incubation modeling of book publications so that the acceleration of the publication process can be optimized.

Keywords: Functional Food, Publication Incubation, Knowledge Management, Communication

To cite this document:

Helmi, R.L,. Ghani, M.W. (2019). Incubation Publication Model for Quality Improvement Of Scientific Book: A Case Study Of Books On Functional Food. Record and Library Journal. 5 (2), 105 - 116. 


\section{Introduction}

Functional foods, in principle, is a material or product that is consumed as the withdrawal of food to improve the functioning of one or more of the target organ and reduces the risk of disease (Tebben, 2005; Kim et al., 2006; Howlett, 2008). World attention to the greater functional food line with a change of mind set and lifestyle of food and health. The main driving factor is the increasing human population of the elderly or the elderly, and the increasing life expectancy. The high human population the greater the impact on the budget allocation for the maintenance of health and prevention of disease. This has encouraged the increasing consumption of a variety of materials and processed products functional food (Howlett, 2008).

According to data from the Food and Agricultural Organization, functional food product trade value reached $\$ 100$ billion and increased by $7 \%$ each year. On the other hand, consumption of functional food has reduced or save 20\% of health care expenditure allocations Food and Agriculture Organization of the United Nations in 2007 in Helmi, 2015; 2015a).

Scientific publications, as one of the chain of research activities, an output that has a double function. From the perspective of knowledge management, the publication is a complex process that includes the externalization of knowledge or dissemination of knowledge that is tacit and explicit of the team as a central actor as a concept model SECI (socialization-externalization combination Internalization) in Figure 1. (Nonaka \& Takeuchi, 1998)

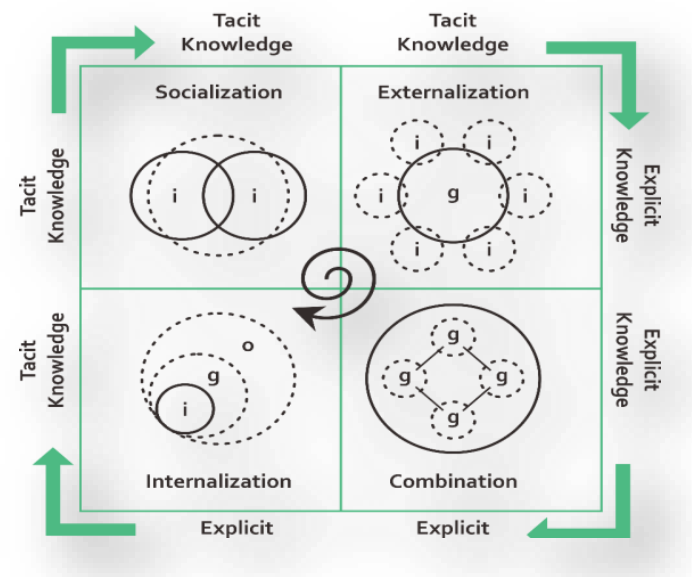

Source: Nonaka, Reinmoeller \& Senno (in Rice \& Rice, 2005)

Figure 1. amber key element of the model SECI

The model is principally focused on the aspects of learning through knowledge transfer processes from tacit to explicit form, explicit to explicit, tacit to explicit and tacit to explicit (Nonaka \& Takeuchi, 1998; Nezafati, Afrazah \& Jalalil, 2009).

Outputscientific publications in book form, is a source of knowledge that can be transferred, arrested (knowledge capture) and divided (knowledge sharing) to the access and the end users (end user). Strategic aspects of the book (science) is in addition to being a source of data and information to enrich science, uncovering the phenomenon in terms of science, provide alternative solutions to a problem of science and technology, as well as a reference of learning for the public Furthermore, the content of the book can also be used as a reference policies and regulations for policy makers (regulator) given field.

The research field of functional foods has been growing rapidly and has been done in the last 10 years, which is reflected also on patent data and prototype products produced (Helmi, 2010; 2010a;

To cite this document:

Helmi, R.L,. Ghani, M.W. (2019). Incubation Publication Model for Quality Improvement Of Scientific Book: A Case

Study Of Books On Functional Food. Record and Library Journal. 5 (2), 105 - 116.

Open access under Creative Commons Attribution-Non Commercial-Share A like 4.0 International Licence 
2011). However, the number of publications in book form is still relatively small. According to the Center for Media and Reproduction (2018), books of research at the Institute issued $22.21 \%$ late publication of books in the field of biological sciences, and only $0.82 \%$ of them book a specific review of functional food, Basically, the purpose of this research specifically to create an incubation scheme to maximize the creative ideas that can be issued by the authors as functional food ingredients. For that aspect of effective communication from the editor to the author of an important aspect that should be emphasized in the incubation modeling to increase the number and speed of functional food ingredients scientific publications in book form.

\section{Case Analysis}

\section{Risk Book Publishing Service}

The publication of scientific activity cannot be separated from the key business processes of book publishing. In general, the publishing business processes from start script to produce a book through the following steps (Figure 2):

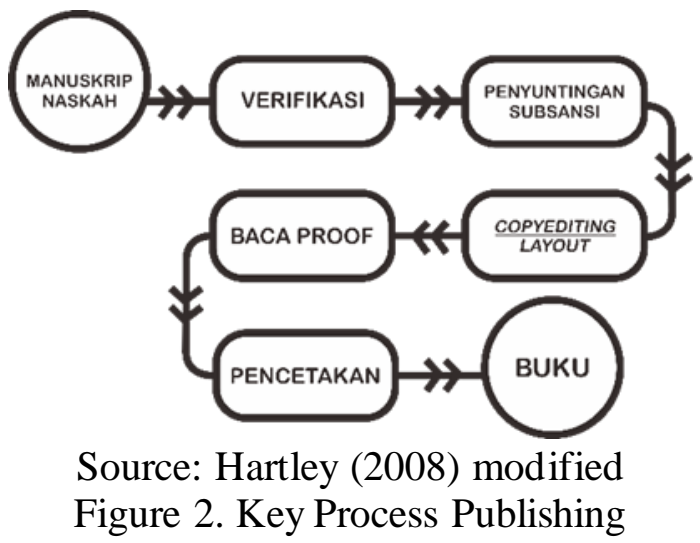

The process of publishing a book, at least involving the editor of the substance (the reviewers or Bestari partners), writer and technical editor (copy editor, layouter, proofreaders). Throughout the complex publishing process involving three parties and have a risk process that can have an impact on delays in the publishing process and the quality of the books produced. Examples of risk assessment services for the rising and highly affect the performance of the issuance are as follows (Table 1):

To cite this document:

Helmi, R.L,. Ghani, M.W. (2019). Incubation Publication Model for Quality Improvement Of Scientific Book: A Case Study Of Books On Functional Food. Record and Library Journal. 5 (2), 105 - 116. 
Rahmi Lestari Helmi | Incubation publication model for quality improvement of scientific book: A case study of books

Table 1. Sample Risk Assessmen Top 5 Book Publishing in Publisher*

\begin{tabular}{|c|c|c|c|c|}
\hline Ranked & Name risk & $\begin{array}{c}\text { The average score of } \\
\text { probability/impact }\end{array}$ & $\begin{array}{l}\text { Total } \\
\text { score }\end{array}$ & Risk category \\
\hline 1 & $\begin{array}{l}\text { Author slow in } \\
\text { responding to } \\
\text { the review }\end{array}$ & $3: 90 / 4: 40$ & $17: 16$ & High \\
\hline 2 & $\begin{array}{l}\text { Author slow } \\
\text { responding } \\
\text { manuscripts } \\
\text { repair }\end{array}$ & 3:50 / 4:10 & $14: 35$ & moderate \\
\hline 3 & $\begin{array}{l}\text { Author slow } \\
\text { responding } \\
\text { manuscripts } \\
\text { improvement }\end{array}$ & $3: 50 / 4: 10$ & $14: 35$ & moderate \\
\hline 4 & $\begin{array}{l}\text { Image material } \\
\text { cover design } \\
\text { does not comply } \\
\text { published }\end{array}$ & 3:50 / 3:30 & $12: 25$ & moderate \\
\hline 5 & $\begin{array}{l}\text { Author slow to } \\
\text { follow up the } \\
\text { script at the } \\
\text { beginning of the } \\
\text { information }\end{array}$ & 3:40 / 3:60 & $12: 24$ & moderate \\
\hline
\end{tabular}

* Refers to the provisions of the Government Internal Control System (SPIP) in accordance with Government Regulation No. 60 of 2008

Source: Center for Media and Reproduction (LIPI Pres) (2018) the data is processed

\section{Publication of pre-publication modeling (prepublish)}

In order to improve the productivity of the publication of scientific books and reducing the risk that would appear throughout the book publishing process, need to be made an incubation mechanism publisher of books focused on the process of preparing the manuscript before the manuscript is published on the issuer (scientific publishing houses). The incubation process of publication includes a complex process of knowled ge exchange among a team of writers and other external parties on the stage prior to the publication of the book was published (Prepublishing) within the framework in Figure 3:

To cite this document:

Helmi, R.L,. Ghani, M.W. (2019). Incubation Publication Model for Quality Improvement Of Scientific Book: A Case

Study Of Books On Functional Food. Record and Library Journal. 5 (2), 105 - 116. 


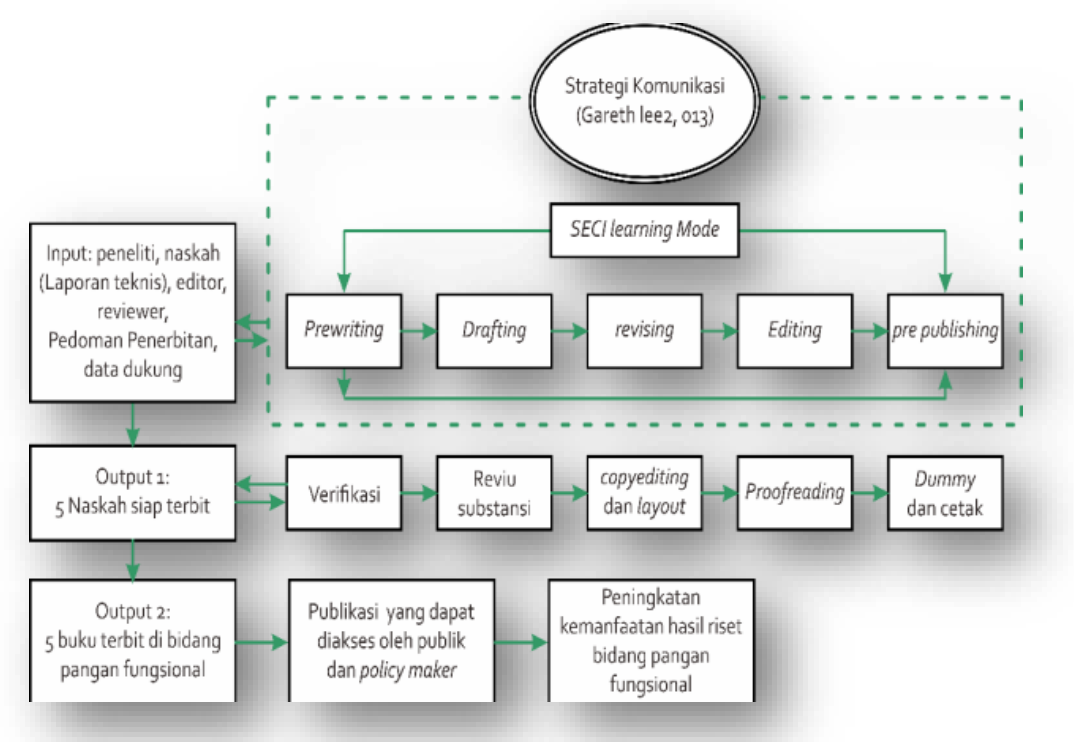

Figure 3. Modeling Framework incubation publication

In this study is identified critical phases that could affect the publishing process. The most critical process, which distinguishes a publisher called scientific publisher with a general publisher, is in the process of scientific publication focused on the manuscript review process substantially (Hartley, 2008; Helmi et al., 2018; Researcher Training Development Center; 2016).

Studies focus on a proposed model of scientific publication from the perspective of knowledge management (knowledge transfer cycle model SECI) and communication strategies. The communication strategy is essential considering the transfer of knowledge involves communication interperpersonal in the context of the organization of the team in the process of publishing a book with This model focuses on the stages and important aspects in the author (pre-publication), starting from the stage of casting the idea of writing (ideation) to the ready availability of textbooks published.

\section{Discussion}

\section{The case study of functional food, books Modeling Incubation For Publication}

The concept of the application of the concept of incubation as part of the creative process is in fact not something new, but the process is more widely used to produce creative arts, both in writing or other tangible products. Novelty aspect in the context of these activities is, when applied in the drafting process of scientific publications or books, which involves learning processes (cognitive, creative) to ensure completeness substantive elements according to the rules and regulations as a scientific book. The novelty of this process also lies in guaranteeing favorable conditions for implementing the knowledge transfer process according to the concept of knowledge management (SECI), the organization of ideas, data and results in manuscript form good publicity. 
Table 3. Description of the analysis aspect of the strengths and weakness manuscripts functional food sector

Manuscripts functional food sector

Aspect

Product tempe Cassava

\section{Technical specifications}

Format

Category publication

Number Chapter/ page

manuscript

Number of books editor (if any)

Total writer

Status of the publishing process

$\begin{array}{ll}\text { Book } & \begin{array}{l}\text { Potpourri } \\ \text { Tractate }\end{array} \\ 5 / 55 & \begin{array}{l}\text { Tractate } \\ 12 / 300 \\ \text { (manuscript) }\end{array} \\ - & - \\ 2 & 10\end{array}$

'Review 7 2`Review

Manuscripts functional food sector

Aspect Product Tempe Cassava

\section{Knowledge access writing and publishing books on pre publish}

Training participation in LIPI book writing and publish

1 of 2 authors trainee LIPI

Press book

2 authors

Participation in the dissemination / workshop publication

Direct consultation procedure and mechanisms for issuance under the responsibility / technical editor LIPI

Access book publishing guidelines LIPI Press
Refer to threguide to publishing

LIPI Press
2 of 10

writers never

participated

in training

1 people

took

socialization

publishing

Not

specifically

before

writing and

publishing

Refer to

threguide to

publishing

LIPI Press

To cite this document:

Helmi, R.L., Ghani, M.W. (2019). Incubation Publication Model for Quality Improvement Of Scientific Book: A Case

Study Of Books On Functional Food. Record and Library Journal. 5 (2), 105 - 116. 


\section{Manuscripts functional food sector}

\begin{tabular}{rr} 
Aspect & $\begin{array}{c}\text { Product } \\
\text { Tempe }\end{array}$ \\
\hline
\end{tabular}

Experience and track record

Write book previous

experience
1 of 2 authors

of popular

science books

ever

published

(module) in

LIPI Press

Coresspondin Coressponding
Had never

written a

book before
Expertise and track record of the author of the book topic g

In support of the manufacturing resource modeling incubation of this publication, is required equalization meaning / creative ideas between writers and editors that are based on effective communication. That requires good interpersonal communication between authors and editors, even starting from the pre-publish. Judy C. Pearson, et al (2012) explain that interpersonal communication is a process that uses the messages to reach similarity of meaning between-least-between two people in a situation that allows for equal opportunity for the speaker and the listener. Therefore, to create an effective publication incubation modeling, process of communication between authors and editors should be based on the commitments that between author and editor is on par (no better or worse).

\section{Communication strategies in modeling Incubation Publications.}

The communication strategy of Lee (2009). This allows it to be applied in the process of exchange of creative ideas that conducted by the authors and editors of scientific publications in applying scheme. It's based on social theory and practice, which adapts commercial marketing techniques to influence people to take the action recommended or make positive changes in their lives. This model will help you equalize ideas or find new ideas when conducting discussions during incubation schemes apply. 8th this step has been the author of (i) adjust to the needs of authors and editors in designing a new publication that 1) Thorough assessment of the situation (the idea) that will be poured at this time, Analyze or identify the situation is the first step in planning a communication strategy. This step helps us establish clear goals, specific and measurable in determining what message you want to achieve by the editor to the author.2) Establish communication purposes, Effective communication can be crucial to the success and sustainability efforts editor to create a comfortable pattern of communication between the editor with the author (speaker). Establish strategic communication objectives and measurable right will help editors to reach similarity of meaning by the author. The purpose of communication editors must the maintain similarity of meaning with the author.

3) Assign people (target) whom you want to discuss, to identify all potential intended to "target" (segment-audience) in this case the author to be understood each his wish in exploring creative ideas by an editor. Setting a target to prioritize targets (author) so they can be understood all the characters entirely by the editor. Simply, the editor must "learn" or seeking information as possible about everything about the writer as a target of communication. 4) Develop materials (ideas) to the people you invite discussion, to develop an effective message that will resonate with the audience, in this case the editor, intended and forced the writer to think, feel, or act in ways that support the communication objectives to be achieved editor. Messages can be informative (submit new facts) or persuasive (change attitudes, change behavior, or persuade the action). Sometimes, the editor should have a progressive 
impact. To persuade the author intended to change behavior, the editor may need to inform and raise awareness about the issue or the program author scientific papers to be achieved. If an editor can "get" the authors to agree with it, understand it, and believe, then they can work together. 5) Choosing the best way to convey your ideas to make the perception. This step will guide the Editor to select a channel, activities and materials that will be the editor used to convey a message to the author. Determining the most effective way to reach an audience (writers). Editors are required to select the best communication style to communicate with the author. There may be more like the editor that has credibility, then the editor must demonstrate communication styles shows that editors have high credibility with the profession. Or is there more like the editor is easy going, then the editor might be able to behave informally when communicating with the author. 6) Creating a strategic plan (timeline) to pour your ideas, to determine where, when, and how each communication schedule will be made to implement the communication plan between editors and authors. In this case the editor should be more proactive in reducing the communication schedule with the writer. 7) Develop these ideas (evaluation). This stage is to convince the author that the editor is able to be invited discuss with the aim of making quality scientific manuscripts. Any discussion is possible in order to understand the outline editor contents of the text you want removed by the author. 8) Running or apply these ideas in writing scientific publications. Editors should be able to help the authors to be able to implement every idea in the script of scientific publications. In this case, the editor is required to have the ability of a professional editor and minimal errors.

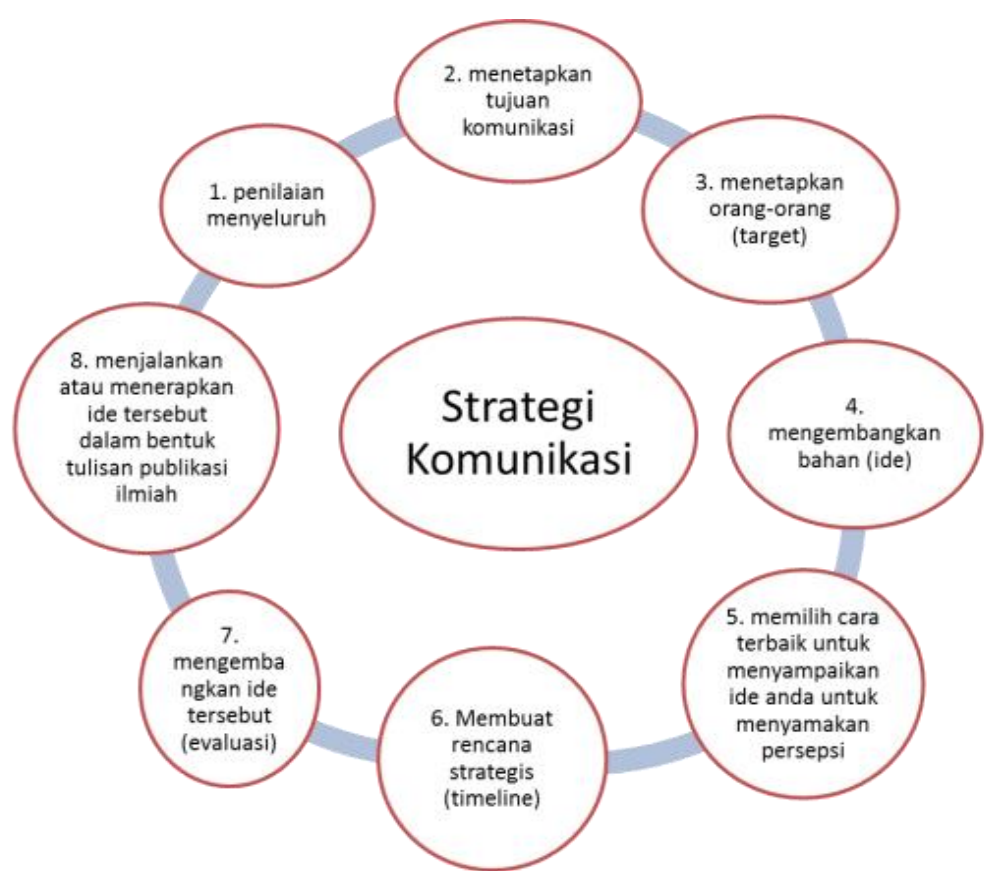

Figure 4. Scheme communication strategy in the implementation process of scientific publication scheme

Keep in mind, to carry out effective communication strategy requires equality in interpersonal communication. With equality in interpersonal communication, the communication strategy models in the scientific publication incubation scheme will give birth to creative ideas that emerged in the prewriting stage. This is very important, given the incubation scheme, scientific publication was created to facilitate the release of creative ideas in order to speed up the time of publication, particularly the field of functional food science.

Effective and efficient communication between the editor and the author is required in the

To cite this document:

Helmi, R.L,. Ghani, M.W. (2019). Incubation Publication Model for Quality Improvement Of Scientific Book: A Case

Study Of Books On Functional Food. Record and Library Journal. 5 (2), 105 - 116. 
publishing world today. The results of the study of the journal manuscript management in South Korea even put the efficiency and transparency of communication between authors, reviewers and editors as the leading base in improving scientific journals in South Korea (Kim et al, 2018, p.133).

Incubation Model publication, publications as an alternative learning. An incubation Model publication of the results of this study can be seen in Figure 4 below:

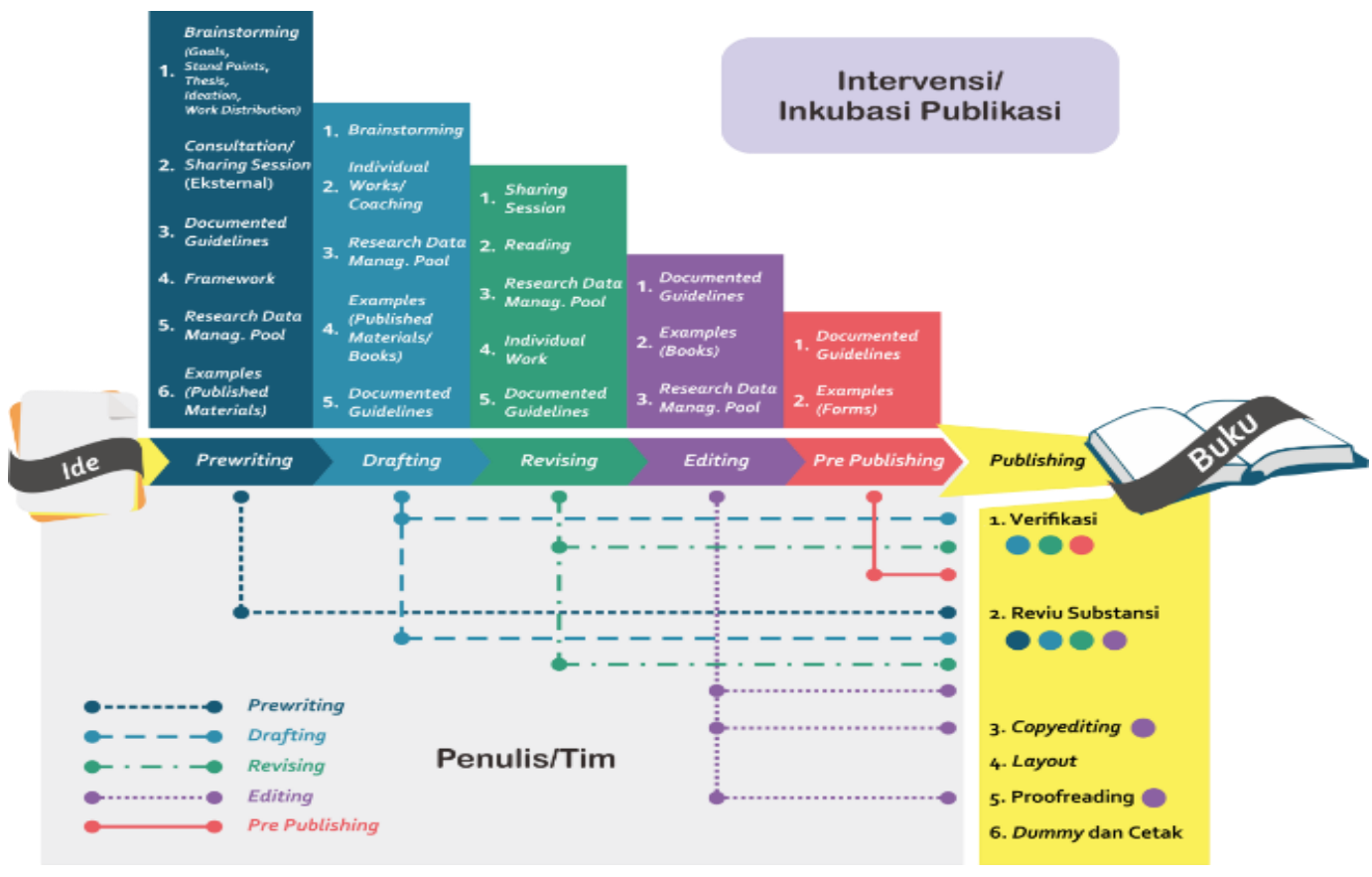

Figure 5. Proposed Modeling incubation publication

Incubation concept in principle conditioning the publication of the learning process to the desired final destination. In the process of incubation publication of this book, in the context of knowledge management involves a complex process, to organize and realize the idea of writing as a form of new knowledge (new knowledge) according to the format and the specified conditions.

According to Rice and Rice (2005), although the transmission mechanism is not described specifically, there is an assumption that in the form of tacit knowled ge requires physical conditions that are close together (proximity) for a process of transfer and exchange of knowledge. In principle, during the processes of knowledge transfer takes place, the exchange of knowledge can take place through a process remotely through the help of telecommunications networks and information networks.

In result of the implementation of the scheme the publication of this incubation, the process of publishing two manuscript material functional food publications with LIPI Press titled Products Based Food Tempe and Applications and Biodiversity, Assembly Clones Superior, and Utilization of Bioresources cassava to support food security reaches the publishing process faster than average target LIPI Press publications in general have a target of 100 days.

Table 4. Manuscript Publishing Schedule Functional Food Ingredients

To cite this document:

Helmi, R.L,. Ghani, M.W. (2019). Incubation Publication Model for Quality Improvement Of Scientific Book: A Case Study Of Books On Functional Food. Record and Library Journal. 5 (2), 105 - 116. 


\section{Manuscript title function food ingredients Manuscript Date of issue}

sign

\begin{abstract}
Biodiversity, Superior Clones assembly, and Unitiization of Bioresources cassava for food security
\end{abstract}

$\begin{array}{ll}\text { October 22, } & \text { January 2, } \\ 2018 & \begin{array}{l}2019(52 \\ \text { buisiness } \\ \text { days })\end{array}\end{array}$

Tempe-Based food products and applications

$\begin{array}{ll}\text { August } & \text { September 12, } \\ 2^{\text {nd }}, 2018 & 2018(29 \\ & \text { working days })\end{array}$

\footnotetext{
* Source: Media Centers and Reproduction (LIPI Pres) (2019) the data is processed
}

Authors' view, that the implementation aspects of the incubation scheme are effectively implemented to support the publication of books number of functional food ingredient capable issued by LIPI Press. However, the cost and time factor becomes very significant constraints in terms of applying the incubation scheme. The incubation scheme requires the use of writers and editors take the time to meet several times. It is quite difficult if not accompanied by budgetary funds and the allocation of time provided by the author and editor. In a publication scheme is not only sufficient incubation with the use of communication technologies such as the Internet. Whereas communication technologies become the fastest growing technology and has the most vital role towards the information society (Gammayan, Nabawi, Alfatih, 2015, p. 122)

\section{Conclusion}

How to publish a book is something that is considered to be difficult for some people, so they tried to get away and avoid it. Writing a book is also sometimes not a priority to researchers, because it remains a priority researcher is writing a journal and not a book.

Write academic papers (journal) is not optional, but mandatory for researchers, so many agencies who want to show a lot more research achievements through journals (Yoon, 2018, P. 84). For that wrote the book takes willpower harder than writing a journal. Culture how to publish a book at the higher of the culture of reading. Our society is basically still at the stage of reading culture. Even then still continue to be pursued in order of reading interest in Ind onesia continues to increase.

Since that is expected by the scientific book publishing incubation scheme will encourage the author / authors in this research field of functional food to want to spread knowledge to the public through a book that is easily understood by the reader. Offensively, it is unavoidable, given the function of a functional food ingredient itself raises one or more health targets, so that the development of the industry itself has a condition called convergence (Lee and Olson, 2007).

During this time the authors show that the book publishing process more stopped because of lack

To cite this document:

Helmi, R.L,. Ghani, M.W. (2019). Incubation Publication Model for Quality Improvement Of Scientific Book: A Case

Study Of Books On Functional Food. Record and Library Journal. 5 (2), 105 - 116. 
of ideas in the middle of the writing process and the lack of commitment to pursue the publishing deadline. With the publication of the scientific publication publication scheme is expected to solve the problems of creative thinking processes that constrain the authors when the writing process takes place.

\section{Acknowledgement}

The authors wish to thanks to the Indonesian Institute of Sciences and particularly Unit and the Media Center for Reproduction(LIPI Press) that has given a lot of data and flexibility authors to conduct research application publication incubation scheme of functional food ingredients. The authors also wish to thank Mrs. Dini Ariani, Mr. Mukhammad Angwar, Mrs. Enny Sudarmonowati, Ibu Sri Hartati, Mr. Ahmad Fathoni, and Hartati as a functional food ingredient research results have been published manuscript by LIPI Press.

\section{References}

Erneste, Pamusuk. (2005). Editing Second Edition. Jakarta: Gramedia Pustaka Utama

Gammayani, Nabawi, Alfatih (2015). Utilization of Information and Communication Technology in coord ination between the National Library with the Provincial Library. Record and Library Journal 1 (2). 120-128. e-ISSN 2442-5168

Hartley, James. (2008). Academic Writing and Publishing: A Practical Handbook. London and New York: Routledge.

Helmi RL. \& Diah AJ. (Ed.). (2015). Functional Food Industry Challenges. Opportunities adoption of data-driven innovation patents in the field of functional food. Jakarta: LIPI Press 2015.

Helmi RL. \& Diah AJ. (Ed.). (2015) Managing Innovation Functional Food Division. Adoption Opportunities Innovation Patent Data Based on Functional Food Sector. Jakarta: LIPI Press 2015.

Helmi, RL, et al (2018). Book Publishing Guidelines LIPI Press. Edition. 2018 Jakarta: LIPI Press.

Helmi, RL. (2010). Assessment of Opportunities for Innovation and Implementation of Development of Functional Food Technology Platform in the field of LIPI. National Seminar on Chemical Engineering UNPAR 2010 with the theme 'Utilization of Biomass for Food, Energy and Chemicals', 22 April 2010 . Univ. Parahyangan Bandung.

Helmi, RL. (2010). Innovation mapping the status of $R \& D$ Results and technology development opportunity in the field of functional food in LIPI. 2nd Indonesian International Conferences on Innovation Entrepreneurship and Small Business, 11-15 july 2010. Organized by SBM ITB in collaboration with CIEL, in Serpong.

Helmi, RL. (2011). Patent-based comparative advantage analysis: a case study on functional food. The 3rd Indonesia International conference on Innovation, Entrepreneurship \& Small Business (IICIES) 2011, 26-28 july 2011. Organized by SBM-ITB in Singapore.

Howlett, J. (2008). Functional food: from sciences to health and claims. Belgia: ILSI Europe

Judy, Person. et. all. 2012. Human Communication. McGraw-Hill Education; 5th edition.

Kim, Choi, Kim, Chung, Lee. (2018). Comparative analysis of the manuscript management systems for scholarly publishing. Science Editing, 5 (2). 124-134. https://doi.org/10.6087/kcse.137.

Kim, JY, Kim, DB, \& Lee, HJ (2006). Regulations on health / functional foods in Korea. Toxicology, $22(1), 112-118$

Lee, SM and Olson DL 2007. Convergenomics: Strategic Innovation in the convergence areas. University of Nebraska Press, USA.

Media Centers and Reproduction (LIPI Press). (2018) Performance Report LIPI Press, 2017. Jakarta: LIPI Pres.

Media Centers and Reproduction (LIPI Press). (2018) Report of the Government Internal Control System (SPIP) Year 2017 Jakarta: LIPI Press.

Nezafati, N. Afrazeh, A. \& Jalali, SMJ (2009). A dynamic models for measuring the knowledge level of organisasi based on Nonaka and Takeuchi models. Scientific Research and Essays, 40 (5), 531542.

To cite this document:

Helmi, R.L,. Ghani, M.W. (2019). Incubation Publication Model for Quality Improvement Of Scientific Book: A Case

Study Of Books On Functional Food. Record and Library Journal. 5 (2), 105 - 116.

Open access under Creative Commons Attribution-Non Commercial-Share A like 4.0 International Licence 
Nonaka \& Takeuchi (1995) .The Knowledge-Creating Company. How Japanese Companies Create the Dynamics of Innovation. New York: Oxford University Press.

Rice, JI \& Rice, BS (2005). The applicability of the SECI models to multiple-organizational endevours: an integrated review. International Journal of Organizational Behavior, 9 (8) .671-682.

Smith, Garret Lee. 2009, Communication Resource Center, Strategic Communication Planning. SAMHSA.

Tebbens, J. (2005). Functional foods and nutraceuticals: The development of value-added food by canadian firms. Ottawa: Science, Innovation and Electronic Information Division, Ministry of Industry

Whitetaker, Anne. (2009). Academic Writing Guide 2010: A Step-by-Step Guide to Writing Academic Papers. City University of Sea

Yoon, Byung-Ho. (2018). 2018 Intermediate-level training course for manuscript editors. Science Editing, 6 (1). 83-84. https://d oi.org/10.6087/kcse.161 